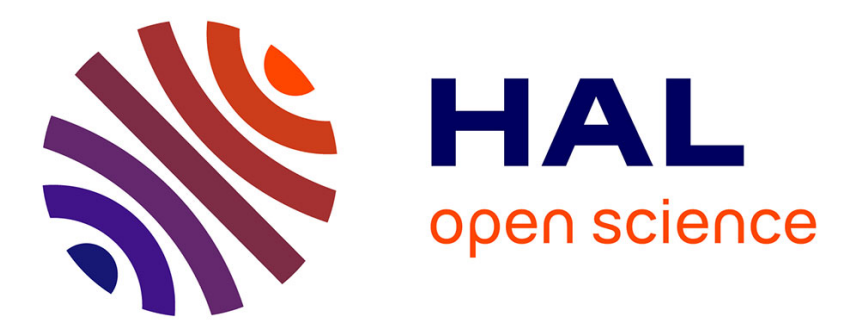

\title{
Super-extended (D3) lymphadenectomy in advanced gastric cancer
}

F. Roviello, C. Pedrazzani, D. Marrelli, A. Di Leo, S. Caruso, S. Giacopuzzi, G. Corso, G. de Manzoni

\section{- To cite this version:}

F. Roviello, C. Pedrazzani, D. Marrelli, A. Di Leo, S. Caruso, et al.. Super-extended (D3) lymphadenectomy in advanced gastric cancer. EJSO - European Journal of Surgical Oncology, 2010, 36 (5), pp.439. 10.1016/j.ejso.2010.03.008 . hal-00594801

\section{HAL Id: hal-00594801 https://hal.science/hal-00594801}

Submitted on 21 May 2011

HAL is a multi-disciplinary open access archive for the deposit and dissemination of scientific research documents, whether they are published or not. The documents may come from teaching and research institutions in France or abroad, or from public or private research centers.
L'archive ouverte pluridisciplinaire HAL, est destinée au dépôt et à la diffusion de documents scientifiques de niveau recherche, publiés ou non, émanant des établissements d'enseignement et de recherche français ou étrangers, des laboratoires publics ou privés. 


\section{Accepted Manuscript}

Title: Super-extended (D3) lymphadenectomy in advanced gastric cancer

Authors: F. Roviello, C. Pedrazzani, D. Marrelli, A. Di Leo, S. Caruso, S. Giacopuzzi, G. Corso, G. de Manzoni

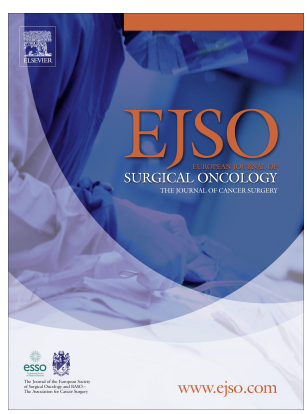

PII:

S0748-7983(10)00064-8

DOI:

10.1016/j.ejso.2010.03.008

Reference: YEJSO 2945

To appear in: European Journal of Surgical Oncology

Received Date: 29 October 2009

Revised Date: 31 December 2009

Accepted Date: 22 March 2010

Please cite this article as: Roviello F, Pedrazzani C, Marrelli D, Di Leo A, Caruso S, Giacopuzzi S, Corso G, de Manzoni G. Super-extended (D3) lymphadenectomy in advanced gastric cancer, European Journal of Surgical Oncology (2010), doi: 10.1016/j.ejso.2010.03.008

This is a PDF file of an unedited manuscript that has been accepted for publication. As a service to our customers we are providing this early version of the manuscript. The manuscript will undergo copyediting, typesetting, and review of the resulting proof before it is published in its final form. Please note that during the production process errors may be discovered which could affect the content, and all legal disclaimers that apply to the journal pertain. 
Title: Super-extended (D3) lymphadenectomy in advanced gastric cancer

Authors: F. Roviello ${ }^{a}$, C. Pedrazzani ${ }^{a}$, D. Marrelli ${ }^{a}$, A. Di Leo ${ }^{b}$, S. Caruso ${ }^{a}$, S. Giacopuzzi $^{b}$, G. Corso ${ }^{a}$ and G. de Manzoni ${ }^{b}$

Authors' Affiliation: ${ }^{a}$ Department of Human Pathology and Oncology, Unit of Surgical Oncology, University of Siena; ITT, Istituto Toscano Tumouri and ${ }^{b}$ Department of General Surgery, University of Verona, Italy

Conflict of interest: None declared

Corresponding Author: Corrado Pedrazzani, Dipartimento di Patologia Umana e Oncologia, Sezione di Chirurgia Oncologica, Policlinico 'Le Scotte'. 53100 Siena, Italy

Tel: ++39 577 585156; Fax: ++39 577 233337; E-mail: pedrazzani@unisi.it

Running Head: D3 lymphadenectomy in gastric cancer 


\section{Abstract}

Purpose: To analyze our experience with D3 lymphadenectomy in the treatment of advanced GC with specific reference to post-operative morbidity and mortality, incidence of para-aortic node (PAN) metastases, and long-term prognosis.

Methods: Short- and long-term results of D3 lymphadenectomy were analyzed in 286 patients with advanced GC.

Results: PAN metastases were demonstrated in 37 patients. PAN involvement was significantly higher in upper third tumours (29\%) compared to middle and lower third (7\%; P $<0.001)$. Eighty patients developed postoperative complications, being pulmonary disorders (6\%), abdominal abscesses (4.5\%) and pancreatic fistulas (3\%) the most frequently observed. In-hospital mortality was $2 \%$. Overall 5 -year survival rate for R0 pT2-4 patients was $52 \%$. When considering survival in relation to nodal involvement, both pN3 and non-regional lymph node metastases (M1a) patients showed a chance of long-term survival: 5-year survival was $31 \%$ for $\mathrm{pN} 3$ and $17 \%$ for M1a cases. Furthermore, the 5year survival rate was remarkably high (about 60\%) even in pN2 and pN3 subsets when no serosal invasion (pT2) was demonstrated.

Conclusions: D3 lymphadenectomy should be considered in specialized centers for curative surgery of advanced GC, especially for upper third tumours, providing that an acceptable morbidity and no increase in mortality can be offered.

Key Words: gastric cancer, surgery, D3 lymphadenectomy, prognosis. 


\section{Introduction}

The reduction in GC mortality reported during recent years by Japanese authors has been attributed to the increased detection of early cancers as well as to the widespread use of extended lymphadenectomy. ${ }^{1}$ To date, little evidence exists from prospective randomized trials to confirm the advantage of extended lymph node dissection compared to limited lymphadenectomy. ${ }^{2,3,4}$ Despite that, longterm results after D2-D3 lymphadenectomy reported by Japanese as well as by dedicated Western centers are definitely better compared to European and US results..$^{5-7}$ In previous publications, we identified lymphadenectomy together with depth of tumour invasion and nodal involvement as independent predictors of survival, demonstrating a more favourable prognosis with extensive nodal dissection. ${ }^{8,9}$

The purpose of the present study was to analyze our experience with superextended (D3) lymphadenectomy in the treatment of gastric cancer with specific reference to postoperative morbidity and mortality, incidence of PAN metastases, and long-term prognosis.

\section{Patients and Methods}

\section{Population under Study}

This study analyzed 286 patients who underwent a macroscopic potentially curative gastrectomy with D3 lymph node dissection for advanced primary gastric adenocarcinomas from January 1993 to June 2007 at two Italian surgical departments (Department of General Surgery and Surgical Oncology, University of Siena; First Department of General Surgery, University of Verona) both part of the Italian Research Group for Gastric Cancer (IRGGC) 


\section{Eligibility Criteria}

The inclusion criteria were as follows: 1) histologically confirmed gastric adenocarcinoma; 2) macroscopic curative (R0-1) resection; 3) advanced (pT24) tumours; 4) systematic and standardized D3 lymphadenectomy (JGCA guidelines). Gastric stump and linitis plastica type tumours were excluded from the analysis. The main demographic and clinical characteristics of the cohort in relation to tumour location are reported in Table 1.

The study was approved by the local ethic committees.

\section{Extent of Gastric Resection}

Gastric resection was performed according to the extent of the tumour in the stomach. Distal subtotal gastrectomy was preferred for tumours located in the lower and middle third of the stomach provided that the proximal resection margin stayed at least $5 \mathrm{~cm}$ from the tumour edge, otherwise total gastrectomy was carried out. ${ }^{9}$

Extent of Lymphadenectomy

Lymphadenectomy was classified and standardized in accordance with the Japanese Gastric Cancer Association (JGCA) guidelines. D3 lymphadenectomy consisted of the removal of regional nodes in the first, second and third level stations as defined by the JGCA. ${ }^{10}$ This procedure has been described in detail elsewhere, and progressively introduced in our practice since $1993 .{ }^{11}$ PAN dissection implied the resection of nodes between the level of the celiac axis and the left renal vein (Station 16-a2) and nodes between the left renal vein and the inferior mesenteric artery (Station 16b1). Dissection of the left upper lateral nodes (Station 16-a2-lat) was generally 
not performed and reserved to patients with enlarged nodes in this area; in particular, in all upper third tumors total gastrectomy with macroscopic evaluation of 16-a2-lat nodes was performed. Lymphadenectomy at the splenic hilum was limited to patients with upper third tumours and enlarged nodes or tumours reaching the greater curvature or the gastric fundus. This was achieved by performing a pancreas preserving splenectomy.

Staging and Lymph Node Classification

Perigastric nodes were dissected from the excised specimen immediately after resection, assigned to the appropriate station according to the JGCA classification, ${ }^{10}$ and sent for histological examination. In order to avoid error in correct lymph node classification after en bloc resection, the second and third tier nodes were subdivided by the surgeon during lymphadenectomy, as previously described in details. $^{12}$

Tumours were staged according to the last version of the pathologic classification (pTNM) of the International Union Against Cancer (UICC). The histological classification followed the Lauren criteria.

Follow-up

All patients were followed-up with a standardized protocol ${ }^{9}$. The median followup period for surviving patients was 57.2 months (range 6-200) and no patients were lost to follow-up procedure.

Statistical Analysis

In 254 cases, there was pathological confirmation that a potentially curative resection (classified as R0) was achieved. Conversely, microscopic residual tumour (R1) or positive peritoneal washing were diagnosed in 32 patients (11.2\%). To evaluate the impact of D3 dissection on long-term survival, we 
avoided to analyze patients with microscopic non-curative (R1) resection, for which the prognosis is well established to be poor and independent from the extent of lymphadenectomy. Postoperative mortality was assessed while deaths unrelated to tumour recurrence were considered censored observations at the time of death. Survival curves were estimated using the Kaplan-Meier method and compared by the Log-rank test. Chi-square test was used for categorical data and ANOVA test for continuous variables.

\section{Results}

Number of Lymph Nodes

The number of excised and positive nodes according to the main characteristics of the tumour for the cohort under study is reported in

Table 2. Of the 286 patients, a total of 13,459 lymph nodes were dissected, with a median number of 45 (range, 15-110) dissected nodes per case. The median number of metastatic nodes was 5 (range, $0-75$ ) in the overall series and 8 (range, 1-75) in $\mathrm{pN}+$ patients.

No difference in the average number of dissected nodes was observed in relation to the depth of tumour invasion $(p T)(P=0.234)$. Conversely, the mean number of metastatic nodes increased from pT2 to pT3 and pT4 tumours $(P<$ 0.001) (Table 2).

Number of Para-Aortic Lymph Nodes

A total of 1,508 nodes were retrieved from the PAN stations, with a median of 5 (range, 0-22). Thirty-seven patients (12.9\%) showed PANs involvement for a total number of 175 nodes. The median number of metastatic nodes in paraaortic area was 3 (range 1-22). 
Frequency of Para-aortic Lymph Node Involvement and pT Category When considering PAN stations, no increase in the average number of dissected $(P=0.972)$ as well as positive nodes $(P=0.074)$ was observed in relation to the depth of tumour invasion (pT) (Table 2). Likewise, the increase in the frequency of involvement of PANs according to $\mathrm{pT}$ classes was not statistically significant $(8.6 \%$ for $\mathrm{pT} 2,16.3 \%$ for $\mathrm{pT} 3$ and $17.4 \%$ for $\mathrm{pT} 4 ; \mathrm{P}=$ $0.142)$.

Frequency of Para-aortic Lymph Node Involvement and Tumour Location

Considering PAN metastases according to the location of the tumour, the frequency of nodal involvement was significantly higher in upper third tumours (26.8\%) compared to middle $(7.5 \%)$ and lower third $(7.2 \%)$ tumours $(\mathrm{P}<0.001)$.

Short-term Results

Eighty of the 286 patients developed postoperative general and surgical complications (morbidity: 28\%); of these, 6 patients died (post-operative mortality: $2.1 \%)$. Table 3 lists the type of complications and their frequency. As shown, pulmonary complications (5.6\%), abdominal abscesses (4.5\%), pancreatic fistulas (3.1\%) and anastomotic leaks (2.8\%) were the most frequently observed complications.

Long-term Results

At the follow-up end date, 150 out of the 286 patients were still alive, and 144 were disease-free. Conversely, 122 patients died because of cancer recurrence, 6 from postoperative complications and 8 from causes other than tumour relapse.

The 5-year survival rate for the 254 patients who underwent $\mathrm{R} 0$ resection was $52.2 \%$ with a median survival time beyond the observation period. The 5-year 
survival rate according to the depth of tumour invasion (pT) was $67 \%$ for pT2 tumours (median beyond the observation period), 39.2\% for pT3 (median, 31.1 months) and $29.1 \%$ for pT4 (median, 10.3 months) $(P<0.001)$. Survival curves in relation to nodal involvement $(\mathrm{pN})$ are illustrated in Figure 1. It is noteworthy that pN3 cases as well as patients with non-regional lymph node metastases (M1a) had a chance of long-term survival.

Figure 2 shows the 5-year survival rate for each $\mathrm{pN}$ subset according to $\mathrm{pT}$ stage (pT2 vs. pT3-4). In node negative patients, the probability of survival was very high independently from pT class $(P=0.615)$. In node positive patients, the 5-year survival rate for pN1, pN2 and pN3 patients was about $60 \%$ in pT2 cases while it decreased progressively in patients with serosal invasion (52.3\% in pN1, $22.2 \%$ in pN2 and $23.6 \%$ in pN3). No difference was observed in M1a patients.

\section{Discussion}

Extent of Lymphadenectomy and Long-term Results

The extent of lymphadenectomy remains a matter of debate in gastric cancer surgery. The well-known randomized Dutch $^{2}$ and British ${ }^{3}$ trials that compared limited (D1) versus extended (D2) lymphadenectomy showed no significant differences in 5-year survival rates between the two groups. This topic was reconsidered by a Cochrane Review ${ }^{13}$ which concluded that "randomized studies show no evidence of overall survival benefit (after D2 dissection), but possible benefit in $\mathrm{T} 3 \mathrm{~N}+$ tumours. These results may be confounded by surgical learning curves and poor surgeon compliance. Non-randomized comparisons suggest a possible survival benefit for D2 in intermediate UICC stages." 
Recently, Wu et al. ${ }^{4,14}$ published the short- and long-term results from a prospective randomized trial comparing limited and extended lymph node dissection carried out at a single specialized institution in Taiwan. Two-arm randomization considered 221 patients and allowed to demonstrate a survival benefit in overall and disease free survival rates after extended lymph node dissection.

\section{Extent of Lymphadenectomy and Tumour Recurrence}

It is well-demonstrated that the great majority of tumour relapses occurs within 3 years ensuing potentially curative (R0) surgery. $^{9,15}$ In the randomized Taiwan trial, the number of patients who relapsed beyond 3 years after extended dissection was limited, but several relapses occurred over time in the D1 group making overall and disease-free survival curves of the two groups to diverge more clearly after 36 months. ${ }^{4}$ This figure was also evident in the final results of the randomized Dutch trial in $\mathrm{pN} 1$ and $\mathrm{pN} 2$ subgroups $^{16}$ and, similarly, in our experience. These data seem to suggest that microscopic residual tumour in surgically un-excised nodes should proliferate and grow in several years leading to overt cancer recurrence. Besides, adjuvant chemo-radiotherapy seems not to influence this aspect as shown in the Intergroup 0116 trial (SWOG 9008). ${ }^{17}$ In addition, there are some evidences that lymph node excision, although negative at microscopic examination, can improve survival ${ }^{18}$ and that lymphadenectomy is beneficial only when the disease is widely encompassed, probably because cancer cells are present in the regional nodes even in cases classified as pN0. ${ }^{19}$ Pros of Extended Lymphadenectomy

Nodal metastases are an early event in gastric cancer and one of the key factors affecting prognosis. Extended (D2) and super-extended (D3) lymph 
node dissection have been suggested to lead to improved staging and better long-term results in several prospective observational series. ${ }^{7,8,20,21}$ Specifically, in a previous study we showed that D2 and D3 lymphadenectomy enables positive nodes clearance that would not have been achieved with limited dissection (D1) in $39 \%$ of cases. ${ }^{22}$ Similar findings were reported by a Dutch study wherein $32 \%$ of the patients had positive nodes removed in the second and third tiers. ${ }^{20}$ In our study, the percentage of patients requiring extended or super-extended lymphadenectomy to remove positive nodes in the second and third levels was $9 \%$ in pT1 tumours, $42 \%$ in pT2, $56 \%$ in pT3, and $67 \%$ in pT4. ${ }^{22}$ Para-aortic Lymph Node Involvement

PAN involvement is regarded as distant metastasis in the TNM classification. However, the results recently reported by Japanese surgeons after superextended lymphadenectomy (i.e. with complete dissection of the para-aortic stations) have cast doubts on this statement. These studies revealed that the incidence of PAN involvement is higher than expected, ranging from 8 to $20 \%$ in patients with advanced gastric cancer and that the 5-year survival rate for this subgroup of patients after super-extended lymph node dissection is 13 to $20 \%$. $^{23-25}$

In our study, PAN deposits were identified in $13 \%$ of the cases with a long-term outcome consistent with that reported in the Japanese literature (Figure 2). In keeping with previous papers, ${ }^{11}$ metastatic spread to PANs was significantly more frequent in upper third compared to middle and lower third tumours (27\% vs. $7 \% ; P<0.001)$.

Morbidity and Mortality after Extended Lymphadenectomy 
Extended and super-extended lymphadenectomy can be associated with large increases in postoperative morbidity and mortality, as reported by trials from the $\mathrm{UK}^{3}$ and The Netherlands, ${ }^{2}$ where the volumes of interventions for centre and surgeon were extremely low and pancreatosplenectomy was routinarely combined with extended lymph node dissection. The Taiwan trial ${ }^{4}$ as well as the interim analysis of a randomized trial from Italy ${ }^{26}$ showed comparable short-term results after pancreas preserving D2 gastrectomy carried out in high volume centres.

The Japanese prospective randomized trial compared D2 and D2 plus paraaortic lymphadenectomy (JCOGS 9501) in 523 gastrectomies performed by experienced surgeons. While morbidity for the super-extended surgery group (28\%) was slightly higher than the extended group (21\%), there was no difference in the incidence of four major complications (anastomotic leak, pancreatic fistula, abdominal abscess, pneumonia) and the reported hospital mortality was $0.8 \%$ for the two group. ${ }^{27}$ Furthermore, no association between postoperative mortality and the extension of lymphadenectomy was reported in a multicenter randomized trial from Poland ${ }^{28}$ and several observational studies published by high volume European centres. ${ }^{6,8,9,29}$ In particular, we have recently demonstrated that it is possible to resemble Japanese results (mortality rate of $0.5 \%$ ) in 203 patients aged 75 years or younger who underwent D2-D3 curative gastrectomy. ${ }^{11}$ In the current experience, $28 \%$ of patients developed postoperative general or surgical complications with pulmonary complaints (6\%), abdominal abscesses (4.5\%) and pancreatic fistulas (3\%) as the most frequently observed complaints, while the mortality rate at $2 \%$ is consistent with best data reported in the literature. 


\section{The Japanese JCOGS 9501 Randomized Trial}

The final long-term results of the JCOGS 9501 randomized trial comparing D2 with respect to D2 plus para-aortic lymphadenectomy have been recently published and failed to show an overall survival benefit for the super-extended group. ${ }^{30}$ Despite this, several considerations should be taken into account: i) the overall survival rates (5-year survival: $70 \%$ ) are at least better by one third than those reported by specialized Western centres in advanced forms; ii) the adopted lymphadenectomy in D2 group included third level nodes (posterior hepatic artery nodes, posterior hepatoduodenal ligament nodes, etc.) in tumour with antral location that lead to a 'D3 lymphadenectomy minus PAN dissection'. The extent of lymphadenectomy is indeed demonstrated by the extremely high number of removed nodes, (mean: 53 for D2 and 73 for D2 plus para-aortic); iii) cases in which macroscopic involvement of PANs was evident at surgery were excluded from the study. As stated by the authors themselves, the percentage of involvement was lower than expected (8\%) and the potential survival benefit possibly weakened.

Certainly this study demonstrated the exceptional high standards of gastric cancer surgery in Japan giving the motivation to Western surgeons to accomplish such a high level of excellence. On the other hand it could lead us to argue that this study does not fit completely to the Western experience where the standards of surgery are not so high and gastric cancer is still diagnosed in a very advanced stage in a high percentage of cases.

Furthermore, the post hoc subgroup analysis based on pathologic $\mathrm{N}$ and $\mathrm{T}$ stages showed a better survival rate in the D2 plus para-aortic group for patients without nodal involvement and for patients with tumour invasion limited 
to the subserosal layer (less than pT3). In this regard, our experience seems to resemble these results. An extremely high chance of cure was observed in our patients with tumors not involving the serosa (pT2) or absence of nodal metastases ( $\mathrm{pNO}$ ), even if survival probability did not reach the results of the Japanese trial. Particularly, long-term results were remarkable in pT2 N2 and N3 patients. One could speculate that in these particular subsets of patients, where the local control of the disease is essential, D3 lymphadenectomy may be of value in improving long-term results. On the contrary, in serosally exposed neoplasms, which are particularly prone to peritoneal dissemination, the extent of lymphadenectomy might not provide a survival advantage with respect to more limited dissection. ${ }^{15}$ However, we emphasize that this is not a randomized trial, and as a consequence we cannot advice this procedure in clinical practice. However, in our opinion the potential benefit of D3 lymphadenectomy cannot be excluded and should be investigated in subgroups of patients.

\section{Conclusions}

Our data are indicative of a potential benefit of super-extended lymphadenectomy in patients with advanced gastric cancer without serosal involvement; furthermore, a chance of cure may also be offered to patients with para-aortic lymph node involvement. Further specifically designed prospective studies should confirm our results and clearly assess which patients may benefit from such an extended procedure. In the meantime, it should only be applied in high-volume specialized centers in the context of a clinical study. 


\section{References}

1. Maruyama K, Okabayashi K, Kinoshita T. Progress in gastric cancer surgery in Japan and its limits of radicality. World J Surg. 1987;11:418-425.

2. Bonenkamp JJ, Hermans $M$, Sasako $M$, van de Velde CJH. Extended lymph-node dissection for gastric cancer. N Engl J Med. 1999;340:908-914.

3. Cuschieri A, Weeden S, Fielding J, et al. Patient survival after D1 and D2 resections for gastric cancer: long-term results of the MRC randomized surgical trial. Surgical Co-operative Group. Br J Cancer. 1999;79:15221530.

4. Wu CW, Hsiung CA, Lo SS, et al. Nodal dissection for patients with gastric cancer: a randomised controlled trial. Lancet Oncol. 2006;7:309-315.

5. Siewert JR, Bottcher K, Roder JD, et al. Prognostic relevance of systematic lymph node dissection in gastric carcinoma. Br J Surg. 1993;80:1015-1018.

6. Roukos DH, Lorenz M, Encke A. Evidence of survival benefit of extended (D2) lymphadenectomy in Western patients with gastric cancer based on a new concept: A prospective long-term follow-up study. Surgery. $1997 ; 123: 573-578$.

7. Roviello F, Marrelli D, Morgagni P, et al. Italian Research Group for Gastric Cancer. Survival benefit of extended D2 lymphadenectomy in gastric cancer with involvement of second level lymph nodes: a longitudinal multicenter study. Ann Surg Oncol. 2002;9:894-900.

8. de Manzoni G, Verlato G, Guglielmi A, et al. Prognostic significance of lymph node dissection in gastric cancer. Br J Surg. 1996;83:1604-1607.

9. Marrelli D, De Stefano A, de Manzoni G, et al. Italian Research Group for Gastric Cancer. Prediction of recurrence after radical surgery for gastric 
cancer: a scoring system obtained from a prospective multicenter study. Ann Surg. 2005;241:247-255.

10. Japanese Gastric Cancer Association (JGCA). The new Japanese Classification of Gastric Carcinoma. $2^{\text {nd }}$ English Edition. Gastric Cancer. 1998;1:1-15.

11. Marrelli D, Pedrazzani C, Neri A, et al. Complications after extended (D2) and superextended (D3) lymphadenectomy for gastric cancer: analysis of potential risk factors. Ann Surg Oncol. 2007;14:25-33.

12. Pedrazzani $\mathrm{C}$, de Manzoni G, Marrelli D, et al. Lymph node involvement in advanced gastroesophageal junction adenocarcinoma. $J$ Thorac Cardiovasc Surg. 2007:134:378-385.

13. McCulloch P, Nita ME, Kazi H, Gama-Rodrigues J. Extended versus limited lymph nodes dissection technique for adenocarcinoma of the stomach (Cochrane Review). In: The Cochrane Library, Issue 4. Chichester, UK: John Wiley \& Sons, 2003.

14. Wu CW, Hsiung CA, Lo SS, et al. Randomized clinical trial of morbidity after D1 and D3 surgery for gastric cancer. Br J Surg. 2004;91:283-287.

15. Roviello F, Marrelli D, de Manzoni G, et al. Italian Research Group for Gastric Cancer. Prospective study of peritoneal recurrence after curative surgery for gastric cancer. Br J Surg. 2001;90:1113-1119.

16. Hartgrink $\mathrm{HH}$, van de Velde $\mathrm{CJ}$, Putter $\mathrm{H}$, et al. Extended lymph node dissection for gastric cancer: who may benefit? Final results of the randomized Dutch gastric cancer group trial. J Clin Oncol. 2004;22:20692077. 
17. Macdonald JS, Smalley SR, Benedetti J, et al. Chemoradiotherapy after surgery compared with surgery alone for adenocarcinoma of the stomach or gastroesophageal junction. N Engl J Med. 2001;345:725-730.

18. Marubini E, Bozzetti F, Miceli R, et al. The Italian Gastrointestinal Tumour Study Group. Lymphadenectomy in gastric cancer: prognostic role and therapeutic implications. Eur J Surg Oncol. 2002;28:406-412.

19. Maruyama K, Gunven P, Okabayashi K, et al. Lymph node metastases of gastric cancer. General pattern in 1931 patients. Ann Surg. 1989;210:596602.

20. Bunt AMG, Hermans J, Smit VTH, et al. Surgical/pathologic-stage migration confounds comparisons of gastric cancer survival rates between Japan and Western countries. J Clin Oncol. 1995;13:19-25.

21. Harrison LE, Karpeh MS, Brennan MF. Extended lymphadenectomy is associated with a survival benefit for node-negative gastric cancer. $J$ Gastrointestinal Surg. 1998;2:126-131.

22. de Manzoni G, Verlato G, Roviello F, et al. Italian Research Group for Gastric Cancer. The new TNM classification of lymph node metastasis minimizes stage migration problems in gastric cancer patients. Br J Cancer. 2002;87:171-174.

23. Kitamura K, Nishida S, Yamamoto K, et al. Lymph node metastasis in gastric cancer in the upper third of the stomach. Surgical treatment an the basis of the anatomical distribution of positive node. Hepatogastroenterology. 1998;45:281-285. 
24. Kunisaki C, Shimada $H$, Yamaoka $H$, et al. Indication for paraaortic lymph node dissection in gastric cancer patients with paraortic lymph node involvement. Hepatogastroenterology. 2000;47:586-589.

25. Maeta M, Yamashiro $H$, Saito $H$, et al. A prospective pilot study of extended (D3) and superextended para-aortic lymphadenectomy (D4) in patients with T3 or T4 gastric cancer managed by total gastrectomy. Surgery. $1999 ; 125: 325-331$

26. Degiuli, M, Sasako M, Calgaro M, et al. Morbidity and mortality after D1 and D2 gastrectomy for cancer: Interim analysis of the Italian Gastric Cancer Study Group (IGCSG) randomised surgical trial. Eur J Surg Oncol. 2004;30:303-308.

27. Sano T, Sasako M, Yamamoto S, et al. Gastric Cancer Surgery: Morbidity and mortality results from a prospective randomized controlled trial comparing D2 and extended para-aortic lymphadenectomy - Japan Clinical Oncology Group Study 9501. J Clin Oncol. 2004;22:2767-2773.

28. Kulig J, Popiela T, Kolodziejczyk P, Sierzega M, Szczepanik A; Polish Gastric Cancer Study Group. Standard D2 versus extended D2 (D2+) lymphadenectomy for gastric cancer: an interim safety analysis of a multicenter, randomized, clinical trial. Am J Surg 2007;193:10-15.

29. Pacelli F, Doglietto GB, Bellantone R, et al. Extensive versus limited lymph node dissection for gastric cancer: a comparative study of 320 patients. $\mathrm{Br} J$ Surg. 1993;80:1153-1156.

30. Sasako M, Sano T, Yamamoto S, et al. Japan Clinical Oncology Group (JCOG). D2 lymphadenectomy alone or with para-aortic nodal dissection for gastric cancer. New Engl J Med. 2008;359:453-462. 
Table 1. Main demographic and clinical characteristics according to the tumour location in the 286 patients under study.

\begin{tabular}{|c|c|c|c|c|}
\hline & $\begin{array}{l}\text { Upper third } \\
\quad(n=82)\end{array}$ & $\begin{array}{l}\text { Middle third } \\
\quad(n=93)\end{array}$ & $\begin{array}{l}\text { Lower third } \\
(n=111)\end{array}$ & Total \\
\hline Age (years) & & & & $\mathrm{P}=0.722$ \\
\hline Mean (range) & $63.2(30-83)$ & $63.3(32-87)$ & $62.2(30-87)$ & $62.8(30-87)$ \\
\hline Gender & & & & $P=0.023$ \\
\hline Male & 60 & 60 & 60 & 180 \\
\hline Female & 22 & 33 & 51 & 106 \\
\hline Lauren classification & & & A & $P=0.510$ \\
\hline Intestinal & 52 & 55 & 57 & 164 \\
\hline Diffuse & 23 & 31 & 44 & 98 \\
\hline Mixed & 7 & 7 & $\bar{x}$ & 24 \\
\hline Depth of invasion (pT) & & D & & $\mathrm{P}=0.004$ \\
\hline pT2 & 38 & 41 & 49 & 128 \\
\hline pT3 & 36 & 38 & 61 & 135 \\
\hline pT4 & 8 & 14 & 1 & 23 \\
\hline Nodal involvement $(\mathrm{pN})$ & & & & $\mathrm{P}=0.012$ \\
\hline $\mathrm{pNO}$ & 19 & 22 & 28 & 69 \\
\hline pN1 & 17 & 35 & 35 & 87 \\
\hline pN2 & 18 & 20 & 22 & 60 \\
\hline pN3 & 5 & 9 & 13 & 27 \\
\hline M1a & 23 & 7 & 13 & 43 \\
\hline
\end{tabular}


Table 2. Overall and para-aortic number of excised and positive lymph nodes according to the main characteristics of the tumour in the 286 patients under study.

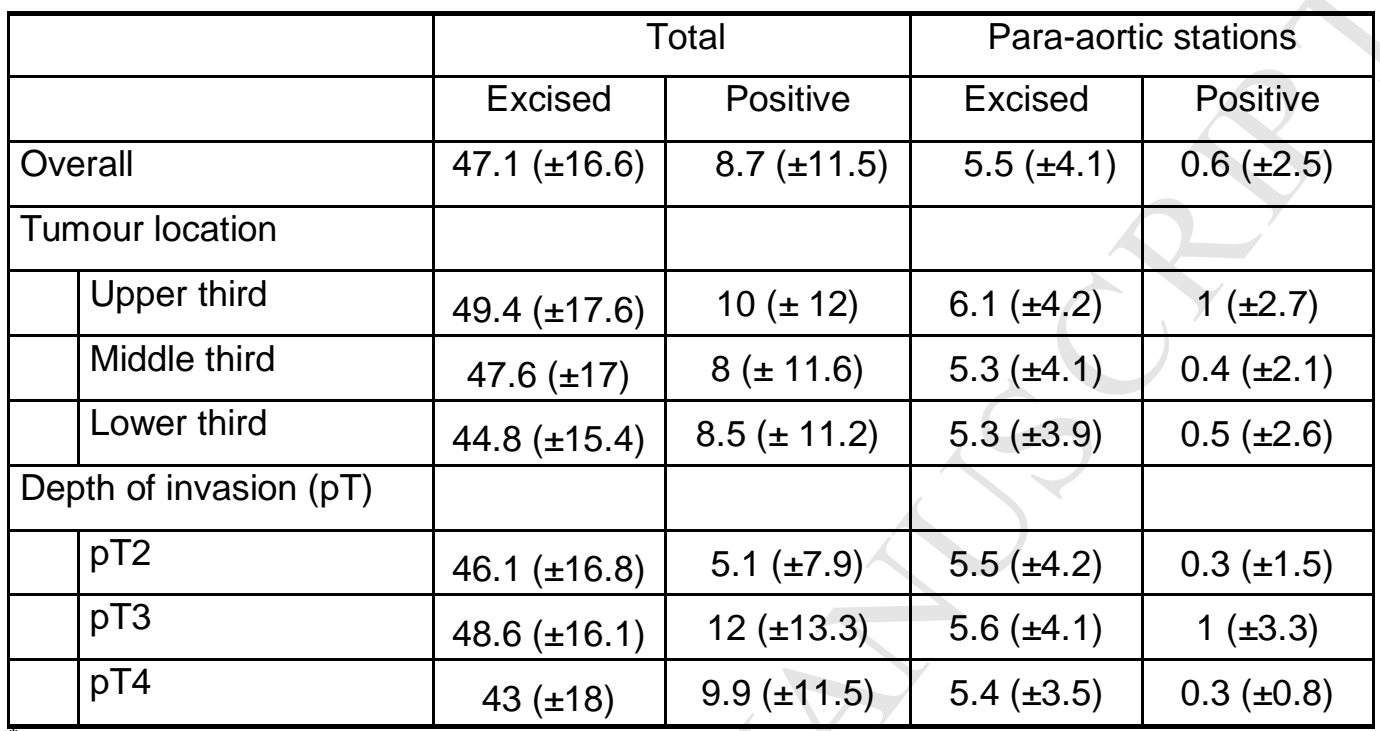

Numbers represent the mean value with $\pm S D$ in parenthesis. 
Table 3. Major post-operative complications observed in the 286 patients under study *.

\begin{tabular}{|l|l|c|}
\hline \multicolumn{2}{|l|}{} & $\begin{array}{c}\text { No. of cases } \\
(286 \text { patients })\end{array}$ \\
\hline \multicolumn{2}{|l|}{ Type of complication } & \\
\hline & Pulmonary & 16 \\
\hline & Abdominal abscess & 13 \\
\hline & Pancreatic fistula & 9 \\
\hline & Anastomotic leak & 8 \\
\hline & Delayed gastric empting & 7 \\
\hline & Lymphorrea & 6 \\
\hline & Paralytic ileus & 3 \\
\hline & Duodenal stump leak & 3 \\
\hline & Abdominal hemorrhage & 3 \\
\hline & Severe pancreatitis & 2 \\
\hline & Anastomotic haemorrhage & 1 \\
\hline & Biliary fistula & 1 \\
\hline & Cardiovascular & 4 \\
\hline & Others & 4 \\
\hline Total & 80 \\
\hline
\end{tabular}




\section{Legend of figures}

Figure 1. Kaplan-Meier estimates of survival probability according to nodal involvement $(\mathrm{pN})$ in the 254 patients who underwent potentially curative gastrectomy with D3 lymphadenectomy. Median survival time was beyond the observation period for $\mathrm{pNO}$ and $\mathrm{pN} 1 ; 27.1(95 \% \mathrm{Cl} 5.6$ - 48.5) months for $\mathrm{pN} 2$; $19.5(95 \% \mathrm{Cl} 0-44.4)$ months for pN3 and $19.4(95 \% \mathrm{Cl} 15.6-23.2)$ months for M1a; $(P<0.001)$.

Figure 2. Kaplan-Meier estimates of survival probability according to the depth of tumour invasion for each $\mathrm{pN}$ subset in the 254 patients who underwent potentially curative gastrectomy with D3 lymphadenectomy. Figure 3a, 3b, 3c,

$3 \mathrm{~d}$ and $3 e$ refers to $\mathrm{pN} 0, \mathrm{pN} 1, \mathrm{pN} 2, \mathrm{pN} 3, \mathrm{M1}$ a subsets, respectively. Median survival times and $P$ values are reported in the Table (Figure $3 f$ ). 


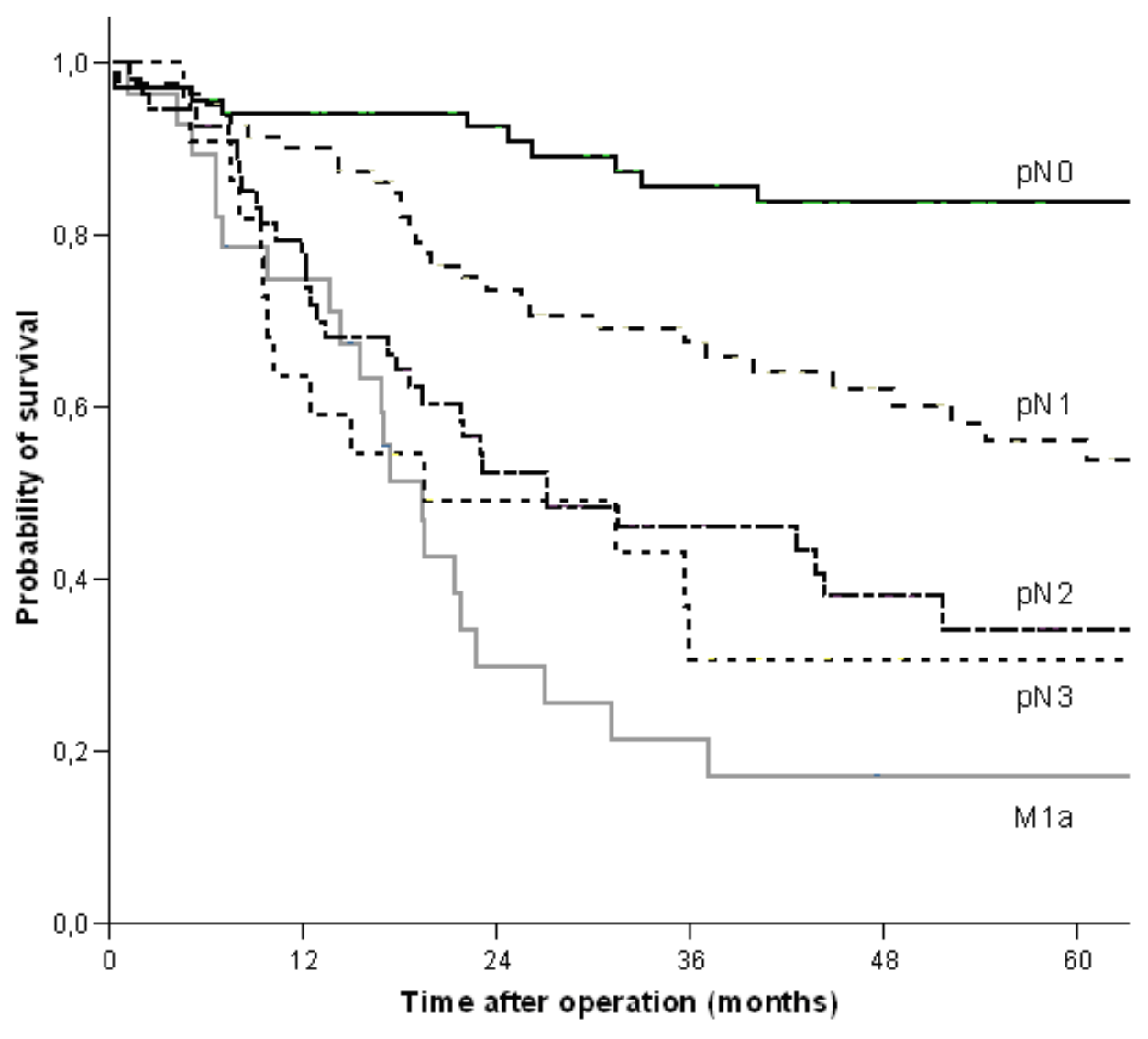



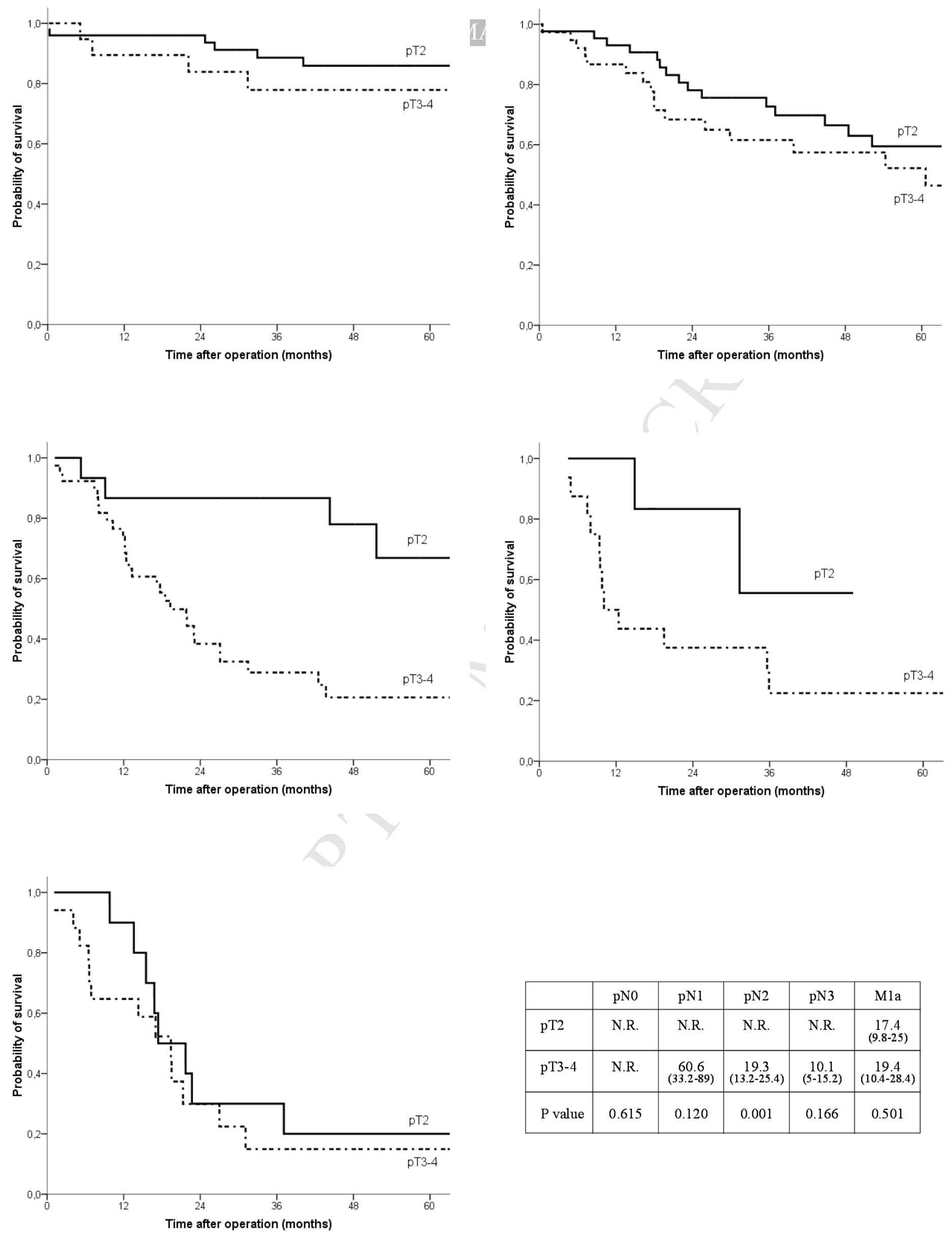

\begin{tabular}{|c|c|c|c|c|c|}
\hline & pN0 & pN1 & pN2 & pN3 & M1a \\
\hline pT2 & N.R. & N.R. & N.R. & N.R. & $\begin{array}{c}17.4 \\
(9.8-25)\end{array}$ \\
\hline pT3-4 & N.R. & $\begin{array}{c}60.6 \\
(33.2-89)\end{array}$ & $\begin{array}{c}19.3 \\
(13.2-25.4)\end{array}$ & $\begin{array}{c}10.1 \\
(5-15.2)\end{array}$ & $\begin{array}{c}19.4 \\
(10.4-28.4)\end{array}$ \\
\hline P value & 0.615 & 0.120 & 0.001 & 0.166 & 0.501 \\
\hline
\end{tabular}

